\title{
RECORDING EARTHEN ARCHITECTURE AT THE PERUVIAN ANDES: THE CASE OF KUÑO TAMBO CHURCH'S HISTORIC WALL PAINTINGS
}

\author{
K.Percy ${ }^{\mathrm{a}}$, C. Hanley ${ }^{\mathrm{a}}$, M.Santana Quintero ${ }^{\mathrm{a}}$, S.Fai ${ }^{\mathrm{a}}$, C.Ouimet ${ }^{\mathrm{a}}$, C.Cancino ${ }^{\mathrm{b}}$, L. Rainer ${ }^{\mathrm{b}}$, L.Villacorta-Santamato ${ }^{\mathrm{c}}$. \\ ${ }^{a}$ Carleton Immersive Media Studio, Carleton University, 1125 Colonel by drive, Ottawa, On, K1S 5B6 Canada \\ kpercy@gmail.com - cims.chanley@gmail.com - Mario_santana@carleton.ca - sfai@cims.carleton.ca - \\ Christian_ouimet@carleton.ca \\ ${ }^{\mathrm{b}}$ Getty Conservation Institute, 1200 Getty Drive, Suite 700, Los Angeles, CA 90049-1684, USA - ccancino@getty.edu - \\ LRainer@getty.edu \\ ${ }^{\mathrm{c}}$ Universidad Católica Sedes Sapientiae, Centro de Estudios y Patrimonio Cultural, Esquina Galileo y Globo Terráqueo S/N \\ Urbanización Sol de Oro. Los Olivos. Lima - Perú - villacorta@ucss.edu.pe
}

CIPA Heritage Documentation

KEY WORDS: 3D imaging, recording, photogrammetry, EDM, Computer-Aided Drawing, wall paintings, conservation, earthen architecture, documentation.

\begin{abstract}
:
According to UNESCO "Earthen architecture is one of the most original and powerful expressions of our ability to create a built environment with readily available resources. It includes a great variety of structures, ranging from mosques, palaces and granaries, to historic city centres, cultural landscapes and archaeological sites" (WHEAP, 2007). This contribution looks at developing effective methods for recording earthen historic structures for their rehabilitation and preservation using the Kuño Tambo church in Peru, which is a Peruvian national historic site that requires serious rehabilitation work, as a case study. This project describes the compilation of an effective metric record of the "state-of-conservation" - "as found" of wall paintings in this important and remote building using a toolbox of different 'off-the-shelf' heritage recording techniques. This approach was applied by Carleton Immersive Media Studio (CIMS), as part of the Earthen Architecture Initiative of the Getty Conservation Institute (GCI).
\end{abstract}

\section{INTRODUCTION}

\subsection{Context}

Over the past 10 years, the Getty Conservation Institute's (GCI) Earthen Architecture initiative has conducted research and projects in identifying assessment, diagnosis and mitigation strategies to overcome the vulnerability of historic sites constructed using earthen techniques. The GCI explains that these structures are likely to be heavily damaged "during an
The project presented in this contribution is currently being conducted at the Church of Santiago Apóstol-henceforth referred to as the Church of Kuño Tambo, which according to the GCI "is the most prominent building in Comunidad Campesina Kuño Tambo, a remote village of 500 inhabitants located southeast of the city of Cusco in the province of Acomayo" (GCI, 2007).

"Constructed with thick mud brick walls, buttresses over a

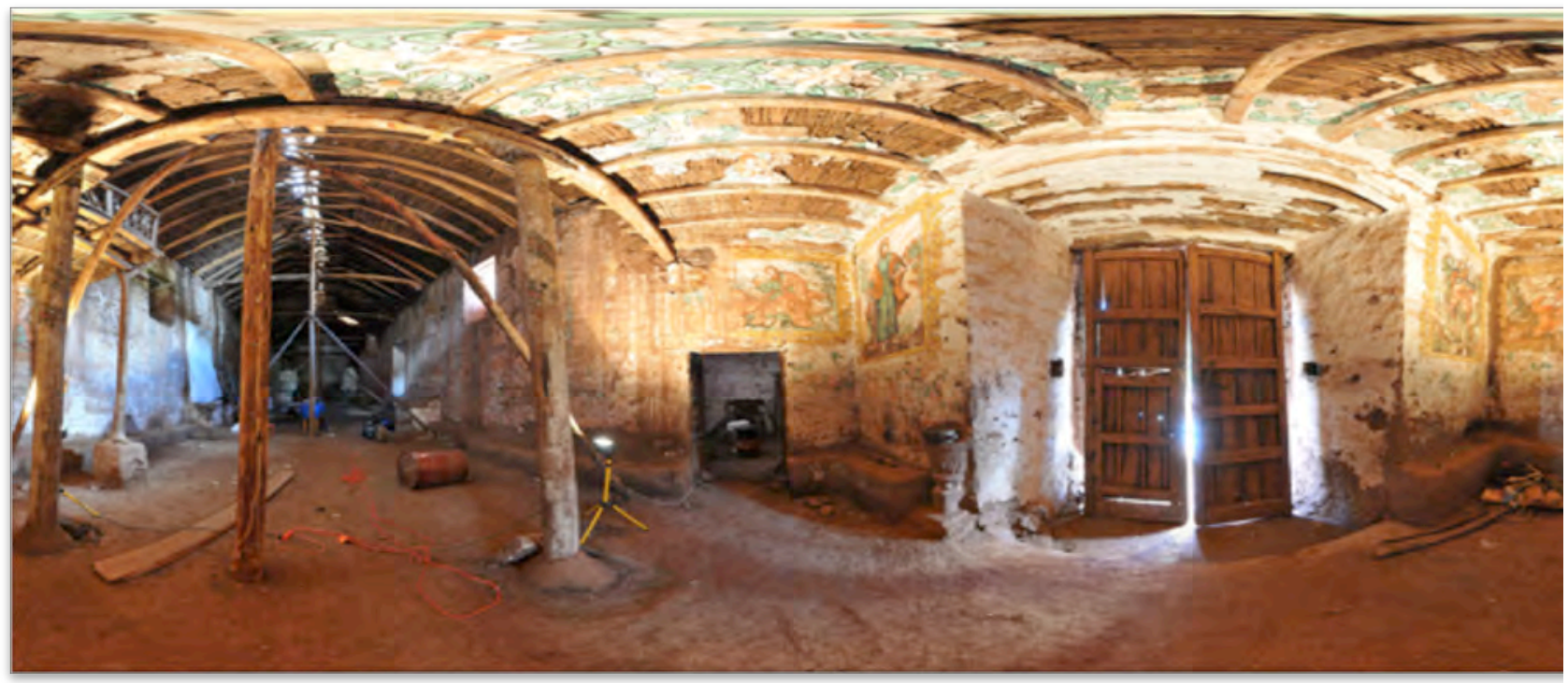

Figure 1. Panoramic spherical image of the interior of Kuño Tambo church, Peru

earthquake, especially if they lack proper seismic reinforcement and regular maintenance" (Lardinois, 2011). rubble stone masonry base course, and a wood-framed gable roof, the $500 \mathrm{~m}^{2}$ church exhibits many of the design features 
and materials typical of rural churches in the region. The entire church appears to have been constructed at the same time, and, although it has been subject to alterations and decay, it appears to have largely retained its original floor plan and mass, as well as many of its original materials. The structure is in fair condition overall, and the preliminary findings indicate that the structural performance of the building is compromised by a leaking roof, inadequate or broken connections at the roof framing, the loss of several exterior buttresses, and settlement of the foundations due to the erosion of the site" (GCI, 2007).

\subsection{Project and Objectives}

Carleton Immersive Media Studio (CIMS) at Carleton University under the auspices of The Getty Conservation Institute (GCI), is currently conducting a project that involves the documentation of the historic wall paintings at the church of Kuño Tambo (Peru), located in an Andean village two hours outside of Cusco. The objective of this project is to rapidly produce a set of ortho-photographs aimed to be the basis of an upcoming wall painting conditions assessment of this XVII century earthen church.

In January 2013, a joint multidisciplinary team of experts from the GCI and CIMS carried out a "heritage recording" and "preliminary condition mapping" of the wall paintings using advanced photogrammetric applications, digital photography, aspheric photography and visual inspection. This first mission had the objectives of preparing:

- A metric corrected photographic record of the wall paintings with sufficient resolution for condition mapping;

- A preliminary visual glossary of damage patterns of the church, which can be used for "condition mapping" and therefore on-going monitoring of the building;

A second mission is scheduled for the spring of 2013 to apply the visual glossary prepared to identify and CAD overlay "damage patterns" into the orthographic images of the wall paintings. The outcome will be a "state of conservation" graphic report to quantify the weathering of the wall paintings surface and plan mitigation strategies.

Furthermore, the team will record the building's envelope using photogrammetry to understand the geometric configuration of the church.

\section{THE DOCUMENTATION PROCESS}

\subsection{Heritage Recording Toolbox: Selection and Implementation}

Photogrammetry was chosen as the primary means for producing images of the frescoes at the church of Kuño Tambo for a number of reasons. First, the photos can be used as historic record photography of the interior wall conditions. Second, because the models can be accessed, manipulated and adjusted by the local conservation team without the need for expensive hardware beyond any good quality digital camera and the software Photoscan produced by Agisoft. Third, the 3D digital models can be used to create sections at a later date, or confirm previous drawings produced by a third party architectural office.
A number of other important considerations were necessary for the determining the approach to documentation in project, one of which involved the remoteness of the site. The team was travelling roughly one hundred kilometres every day from Cusco to reach Kuño Tambo. The timeframe (high speed documentation was an asset), transportation, and the limited means available, all played an important role in determining the chosen methods.

Other considerations included the acquisition of a basic set of measured drawings of the church prior to the trip. Because preliminary plans and sections had already been drawn in AutoCAD, recording was focused on capturing high resolution images of the wall paintings.

During the recording process three stages of work were conducted: given the poor illumination conditions inside the church, the first stage of documentation involved experimenting with the use of artificial lighting for capturing photographs aimed at generating smooth photogrammetric processing and an accurate digital model (Figure 2).

The second stage involved measuring control points with a Total Station. Using the control points, it was possible to scale and orient the photogrammetric models, and to link the survey to the existing measured drawings.

The controls were selected on sharp edges of the wall painting's features to prevent the use of any targets that might damage the integrity of these important character-defining elements of this historic building.

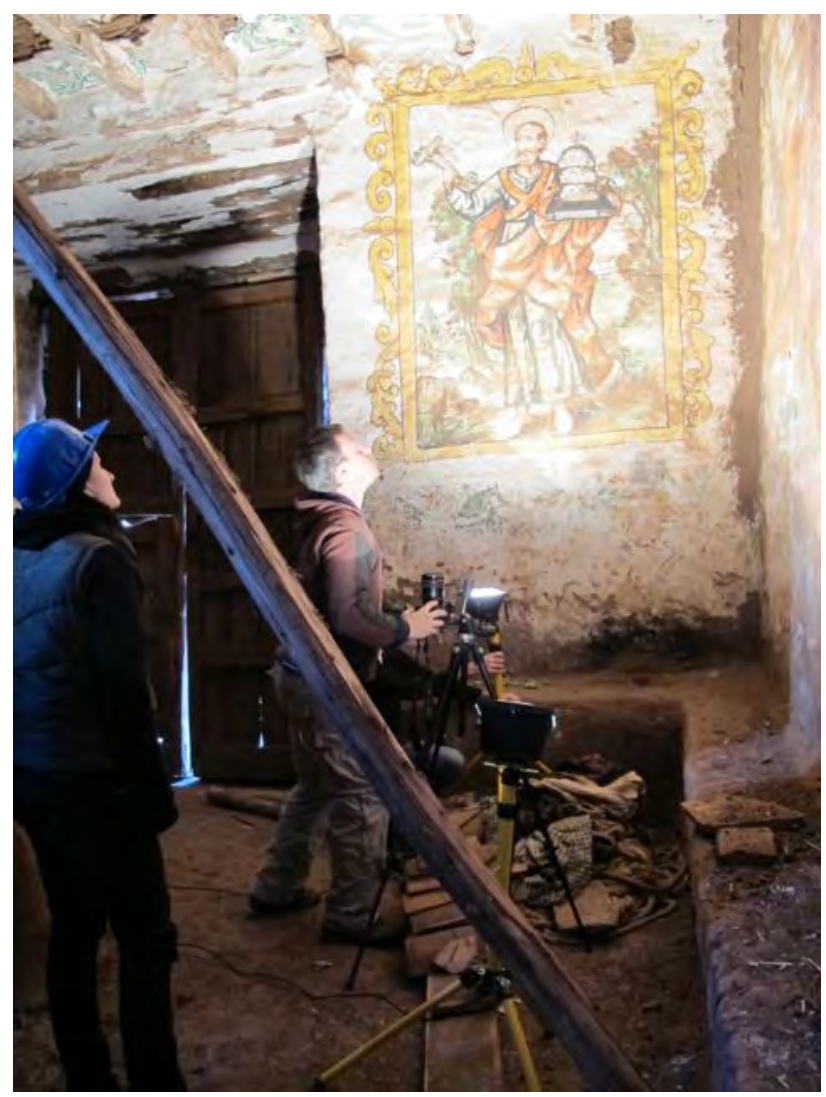

Figure 2. taking photograph using artificial lighting. 
Because the results of the first stage were excellent, it allowed the use of artificial lighting (flashes and lighting) at the third stage. The selected resolution to take overlapping photographs was chosen using the CIPA $3 \times 3$ rules to cover the entire surfaces of the wall paintings. This resolution was used to obtain ortho-images of the desired scale that would easily permit accurate surface condition identification and mapping.

The images were named according to the GCI's image protocol and each of the photogrammetric models was processed using Agisoft's Photoscan.

The resulting photogrammetric geometry or mesh of each of the six faces was then built, resulting in a complete 3D model of the space. The same photos used to build the basic digital models were then used to build the textures.

\subsection{Panoramic Photography}

A set of several full spherical panoramic photographs were prepared from specified locations throughout interior and exterior of the church as reference to the photogrammetric processing and preparation of ortho-photographs for referential purposes (Figure 1).

Using the software PTGui, the resulting panoramas were prepared by stitching 8 overlapping images for a complete coverage of 360 degrees of the captured scene ( 6 horizontal and two bottom and top views). The images were taken using a Nikon D300 DSLR camera (12.3 megapixel DX format CMOS sensor) equipped with a fisheye Nikkor lens of $10.5 \mathrm{~mm}$ that covers a Field of View of around $180^{\circ}$ diagonal. To prevent major effect of parallax a Nodal Ninja 3 panoramic adapter was used.

\subsection{Condition Record Photography}

During the fieldwork, condition record photography was taken from selected areas identified by wall painting specialist (Figure 3). These photographs were used for the preparation of a weathering atlas of decay patterns present on the wall painting surfaces, such as cracks, spalling, detachment, etc.

Each photo was identified on a photo key plan to understand the location of these damage patters and reference to the glossary.

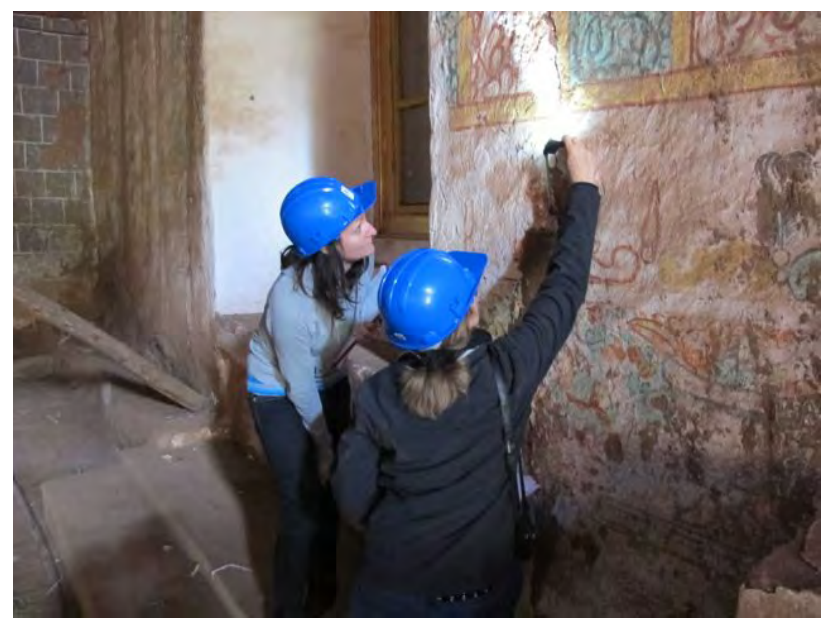

Figure 3. Identification of conditions using visual inspection

\section{PROCESSING}

\subsection{Photogrammetric Image Capture and Processing}

The main hall of Kuno Tambo is a long rectangular space which was divided into six sections and then subdivided as needed for the construction of the photogrammetric models (Figure 4). The western wall of the church was covered over for conservation purposes, therefore the accessible walls included only the long north and south walls, and the east wall which was subdivided by a balcony into the lower entrance and the upper choir loft.

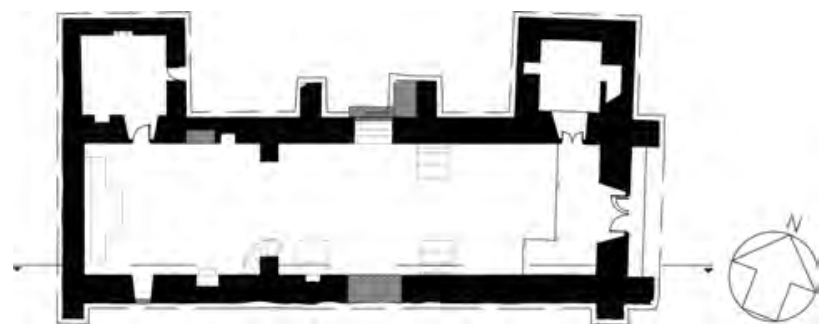

Figure 4. Plan of the church of Kuno Tambo

The interior elevations were photographed with a minimum of $60-80 \%$ overlap between images. Because the requested orthographic images were to be printed at a 1:10 scale, the model images had to be separated and taken at a lower resolution so that the entire wall could be modelled at a scale, which allowed for manageable file sizes in Photoscan.

The images captured for the texture were taken with only $5-10 \%$ overlap, but at a higher resolution. The east and west walls required about 50 photos each for the production of the models, and 25 photos each for the texture. The south wall was much smaller and required half as many photos for the model and texture respectively.

Once the images were sorted according to their orientation and function (model or texture) in Adobe camera raw, the white balance was adjusted, vignetting and distortion correction were removed using the camera profile, and the colour temperature was adjusted to ensure a uniform colour balance across all the elevations.

The next stage was to build the geometry in Photoscan. Agisoft PhotoScan is a $3 \mathrm{D}$ reconstruction software that creates textured mesh models using photographs (Agisoft). The software is able to take two images of the same subject taken from different angles and create a model from the pairing of the two photographs. If many images are combined, it is possible to create a digital model composed of triangles to form a mesh onto which a high resolution image, or texture, can be projected.

Once each section of the church was modelled using the photographs in Photoscan, the resulting mesh was cleaned up in Geomagic. Geomagic is a software owned by 3DSystems (Geomagic). We used the Studio version of the software which contains many useful mesh altering tools including: hole fixing, mesh slicing and edge repairs. Any gaps or holes in the mesh were filled or corrected to ensure that the texture had a complete surface on which to project (Figure 5). 


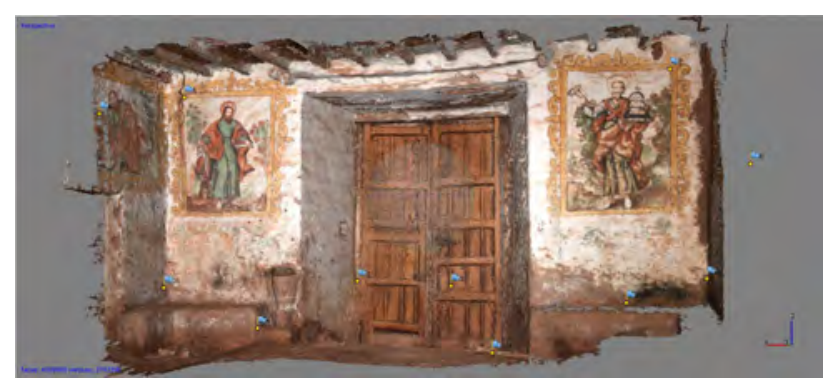

Figure 5. Final photogrammetric model of the east entrance with scaled survey points picked (blue flags) and texture applied

Finally, the orthographic models and textures of each elevation were imported into AutoCAD where they were scaled according to a survey which was carried out concurrently to the photos being captured on site. Matching the image to the survey was simply a matter of picking two specified points on the images (Figure 5), using the scale command in AutoCAD, and snapping the selected points on the image to the imported survey points.

The final ortho-image (Figure 6) can then be printed from a standard sheet in AutoCAD with the glossary and a titleblock containing relevant project information. the Getty Conservation Foundation to ensure the conservation of the historic wall paintings.

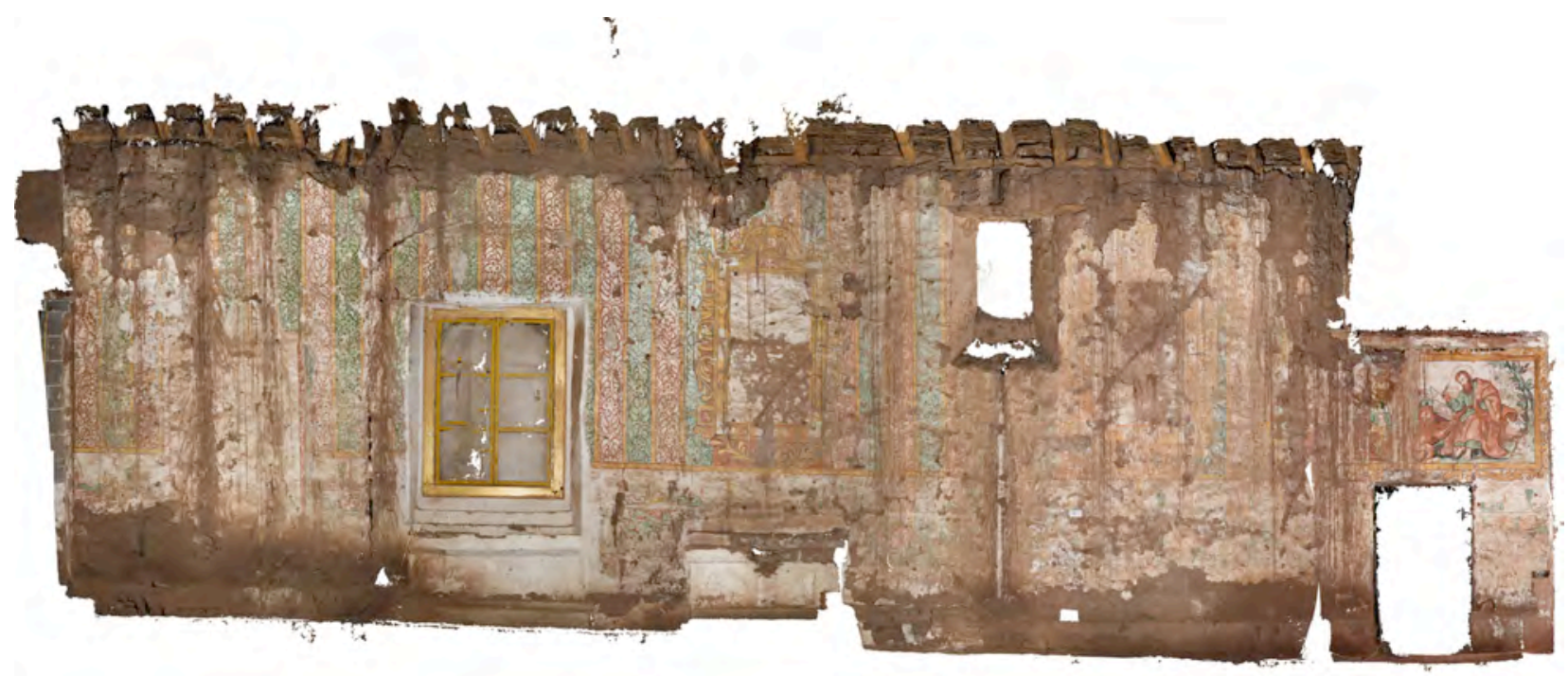

Figure 6. South façade, orthographic elevation of frescos generated from a photogrammetric model

\subsection{Preparation of the Visual Glossary}

The various deterioration conditions of the church were assessed and categorized as 1) Structural, 2) Plaster Layer(s), 3) Paint Layer(s), 4) Surface, and 5) Previous interventions. A visual glossary was created to identify and define these unique conditions found in the church, which significantly affect the original wall paintings.

Graphic symbols were then created to correspond with the derived definitions of the glossary. These symbols (both digitally and manually generated) will be used in the upcoming phase of the project to thoroughly map the deterioration conditions of the interior wall surface in its entirety (Figure 7).

The conditions assessment and visual glossary of the church is an important element for the future seismic retrofit initiative of 


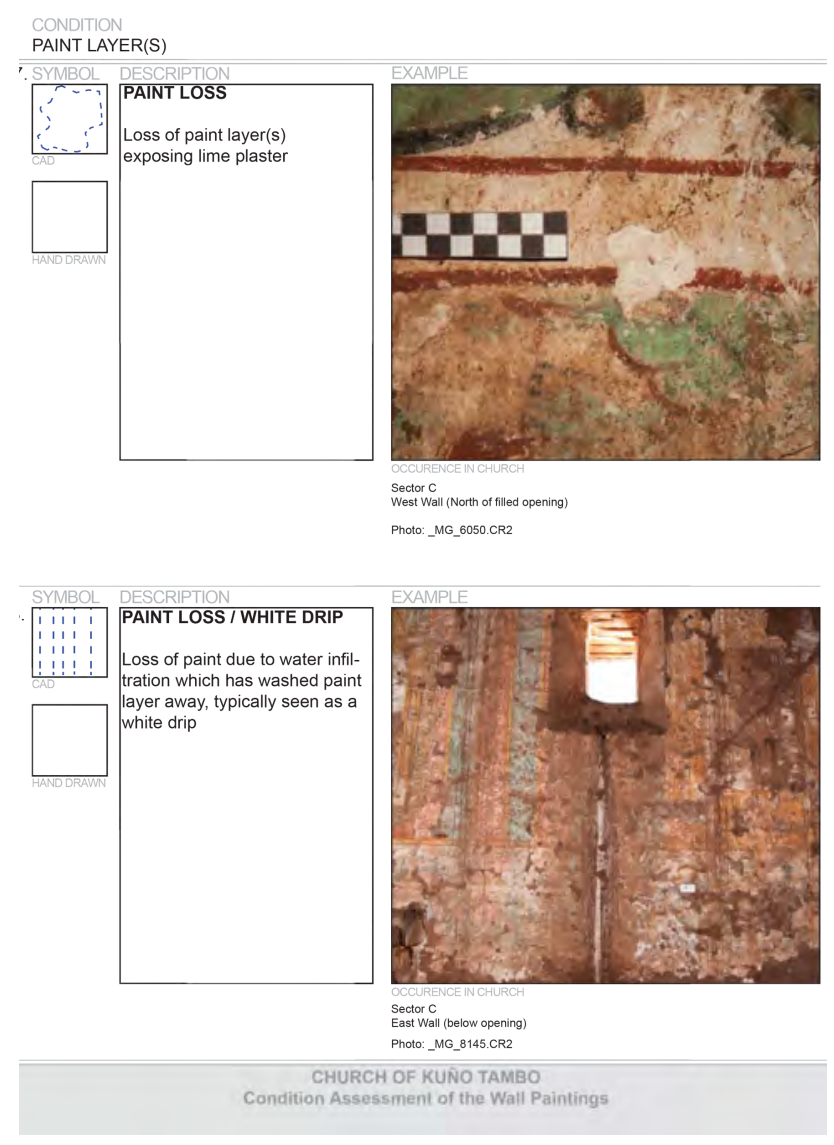

Figure 7. Example of the condition assessment glossary

\section{DISSEMINATING AND SHARING KNOWLEDGE WITH LOCAL STAKEHOLDERS}

The community of Kuño Tambo is very involved in the conservation efforts to repair this church, for this reason the Getty Conservation Institute (GCI) and the Carleton Immersive Media Studio (CIMS) in collaboration with the Cusco branch of the Peruvian Ministry of Culture prepared a workshop and demonstrations, in which the community experienced first hand the undergoing work carried out by the specialist taking part on the first mission to Peru. The photogrammetric approach, condition assessment and the overall aims of the project were presented

\section{CONCLUSIONS}

This contribution provides a comprehensive approach that is based on developing "the how" according to the "why" and "when" in heritage recording for rapid and accurate assessment of wall painting. The "how" relates to the integration of surveying techniques to capture the correct geometry of the wall painting surface and the shape (colour and feel) for condition assessment. The "why" relates to the purpose of the records, in this case for conservation and the "when" relates to the requirements of the ultimate beneficiaries of this information, the community of Kuño Tambo and the advancement of seismic retrofit research of earthen architecture buildings.

Although there is a vast array of digital techniques of heritage recording that facilitate the capture of historic places quickly and accurately using active (eg. 3D Scanning, Total Stations, etc.) and passive sensors (eg. photogrammetry, rectified photography, etc.), it is important to evaluate what is the required "final " set of deliverables, timeframe available, and the level of expertise available. Heritage documentation projects should not undermine the ultimate goal of producing an accurate diagnosis of the fabric required to extend their life cycle for the benefit of present and future generations.

\section{FURTHER RESEARCH}

Given the team's expertise in 3D modelling and the potential of on-going photogrammetric developments, further research could be conducted in the following areas:

- 3D models resulting from photogrammetry and their integration to Building Information Systems (BIM) application to record the current condition of earthen architecture historic places;

- Procedures for actively monitoring earthen historic structures using new advances in photogrammetry;

- $3 \mathrm{D}$ condition assessment using meshes resulting form photogrammetry for earthen architecture linked to graphic glossary of deterioration patterns;

- Development of a set of guidelines for rapid assessment and recording of earthen architecture structures using low-cost surveying techniques, such as photogrammetry.

\section{ACKNOWLEDGEMENTS}

The authors wish to thank The Getty Conservation Institute (GCI), the community of Kuño Tambo and the Peruvian team for the opportunity to collaborate in this important contribution to science in conserving earthen architecture in Peru and around the world.

\section{REFERENCES}

\section{References from books:}

CERKAS, UNESCO World Heritage Centre, CRATerre-EAG "Conservation manual: For Earth Architecture Heritage in the pre-Saharan valleys of Morocco" (2005) . pp 220. Feilden, Bernard. "'Photogrammetry and
Earthquakes"." Between Two Earthquakes. Marina del Rey,
California: Getty Conservation Institute, 1987. Pp. 63-69.

Houben, H. Guillaud, H. "Earth Construction" ITDG, CRATerre-EAG, France. Pp. 123.

ICOMOS UK 'Guidelines to Recording Historic Buildings' (1996). Pp. 120-122.

Patias, P. Santana Quintero, M. Introduction to Heritage Documentation, In CIPA Heritage Documentation best practices and applications, Stylianidis, E. Patias, P. Santana Quintero, M. ed. The ICOMOS \& ISPRS Committee for Documentation of Cultural Heritage. The ISPRS International Archives of the Photogrammetry, Remote Sensing and Spatial Information Sciences, Vol. XXXVIII-5/C19. ISSN 1682-1750. Pp 20-30.

\section{References from websites:}

Agisoft. Product description http://www.agisoft.ru/products (24 Jun. 2013) 
Agisoft. Photoscan pro tutorial. http://www.agisoft.ru/tutorials/photoscan (24 Jun. 2013)

English Heritage 'The Presentation of Historic Buildings survey in CAD' (2005), Swindon, UK. http://www.helm.org.uk/guidance-library/historic-buildingsurvey-in-cad/ (24 Jun. 2013)

Eppich, E. Chabbi, A. ed. 'Illustrated Examples Recording, Documentation, and Information Management for the Conservation of Heritage Places' The Getty Conservation Institute, J. Paul Getty Trust (2007), retrieved from: http://www.getty.edu/conservation/publications resources/pdf publications/recordim vol2.html (24 Jun. 2013)

Geomagic, Geomagic Studio Overview http://www.geomagic.com/en/products/studio/overview Jun. 2013)

The Getty Conservation Institute Facebook page https://www.facebook.com/media/set/?set=a.444655202271823. $102710.294993627237982 \&$ type $=3$ (24 Jun. 2013)

Letellier, R. Schmid, W. LeBlanc, F. 'Guiding Principles Recording, Documentation, and Information Management for the Conservation of Heritage Places' The Getty Conservation Institute, J. Paul Getty Trust (2007), http://www.getty.edu/conservation/publications resources/pdf publications/recordim.html (24 Jun. 2013)

Lardinois, S. Getty Conservation Institute- Getty Iris. "A Project of Seismis Proportions" (2011) http://blogs.getty.edu/iris/a-project-of-seismic-proportions/. (24 Jun. 2013)

Lardinois, S. Getty Conservation Institute- Getty Iris. "A Project of Seismis Proportions" (2011) http://blogs.getty.edu/iris/a-project-of-seismic-proportions/. (24 Jun. 2013)

Tolles, E.L. et.al. "Seismic Stabilization of Historic Adobe Structures" The Getty Conservation Institute, J.Paul Getty Trust (2000)

http://www.getty.edu/conservation/publications_resources/pdf_ publications/pdf/seismicstabilization.pdf (24 Jun. 2013)

UNESCO World Heritage Centre - World Heritage Earthen Architecture Programme (WHEAP)." UNESCO World Heritage Centre. (2007) http://whc.unesco.org/en/earthen-architecture/ (24 Jun. 2013) 